\title{
Upright versus recumbent position during first stage of labor among primipara women on labor outcomes
}

\author{
Afaf Mohamed Mohamed Emam*1, Ahlam Eidah Al-Zahrani ${ }^{2}$ \\ ${ }^{1}$ Faculty of Nursing, Benha University, Benha, Egypt \\ ${ }^{2}$ Faculty of Nursing, King Abdulaziz University, Jeddah, Saudi Arabia
}

Received: December 13, 2017

Accepted: February 8, 2018

Online Published: March 15, 2018

DOI: $10.5430 /$ jnep.v8n7p113

URL: https://doi.org/10.5430/jnep.v8n7p113

\begin{abstract}
Objective: The aim of this study was to assess the effect of upright versus recumbent position during the active phase of first stage of labor among primipara women on labor outcomes in term of progress, duration of labor, method of delivery, neonatal outcome and maternal satisfaction with assumed position.

Methods: Quasi experimental design was used. The study was conducted in the labor unit in obstetric department at Benha University Hospital. A purposive sample of 100 parturient women in 1st stage of labor were recruited in the study, they divided into two groups; upright group (50) and recumbent group (50). Data were collected through four main tools: Structured Interviewing questionnaire sheet, Structured Observational Checklist include (Partograph and Apgar score), Visual analogue pain intensity scale and maternal satisfaction with assumed position questionnaire.

Results: It revealed that high statistical significant difference between the upright and recumbent groups in term of decreases interval and increases duration, frequency and intensity of uterine contraction, cervical dilatation and fetal head descent/fifth among the upright group. While the recumbent group showed less progress. Moreover, the recumbent group expressed more pain score, consume longer duration of 1st, 2nd, 3rd stage of labor than the upright group and statistical significant difference in Apgar score of the neonate during both first and fifth minute. In addition, the upright group had higher satisfaction scores compared to those assumed recumbent positions $(p<.001)$.

Conclusions: Upright position had positive effect on progress of labor, decreased duration of the three stages of labor, better neonatal outcomes and improving parturient women's satisfaction with assumed position. The study recommended that all parturient women in low-risk labor should be informed about the benefits of assuming upright positions during first stage of labor, and be encouraged and supported to use them.
\end{abstract}

Key Words: First stage of labor, Upright position, Recumbent position, Labor outcomes

\section{INTRODUCTION}

Childbirth is unique process for women. It is important period in woman's life and ends with giving baby which is the most wonderful moment in women's life, highly joyful experience and celebrated event to their families. ${ }^{[1]}$ The process of giving a baby occurs in several stages which lasting from hours to few days starting from onset of regular uterine contraction to deliver the baby and placenta. The first stage of labor is longer and painful. In primipara, usually lasts from 12 to 16 hours and about 6 to 8 hours for multipara. First stage of labor consisted of three phases; latent, active and transitional phase. ${ }^{[2]}$

A previous study conducted by Lawrence et al. ${ }^{[3]}$ mentioned Egypt.

Published by Sciedu Press 
that, it is more common for women in both high- and lowincome countries giving birth in health facilities, to labor in bed. There is no evidence that this is associated with any advantage for women or babies, although it may be more convenient for staff. Observational studies have suggested that if women lie on their backs during labor this may have adverse effects on uterine contractions and impede progress in labor, and in some women reduce placental blood flow.

As well as Priddis et al. ${ }^{[4]}$ reported that, position during labor is influenced by cultural factors, obstetric practices, place of delivery, technology and preference of the mother and health care providers. Maternal positioning during labor affects many aspects of the anatomy and physiology adaptations needed to influence all aspects of labor including powers, passage, passenger and psyche. In addition, influences the characteristics and effectiveness of uterine contractions, fetal well-being, maternal comfort, course of labor and enhancing satisfaction with the birth experience.

Generally, women lie in the recumbent position (including supine, semi-recumbent and lateral) during first stage of labor makes it easier for nurses to monitor progress and carry out procedures that restrict mobilization such as abdominal examination to assess uterine contractions, to perform vaginal examinations to assess progress of labour and invasive manoeuvres, to check the fetal head position and to assess the fetal heart rate as stated by Martin et al. ${ }^{[5]}$ Unfortunately, Recumbent positions results in supine hypotension diminished uterine activity and a reduction in the dimensions of the pelvic outlet Leifer. ${ }^{[6]}$

Conversely, it is necessary for women to deliver naturally to walking around, standing, sitting, kneeling or squatting, which allow "gravity effect" to speed the cervix dilation. Gizzo et al. ${ }^{[7]}$ reported that an upright position (including walking, sitting, standing, kneeling and squatting) during first stage of labour have less vulvar edema and less blood loss. If the membranes are intact, the woman is allowed to walk about. This attitude prevent vena cava compression and encourage descent of the head. Ambulation can reduce the duration of labour, need for analgesia and improve maternal comfort.

Actively promoting and encouraging women to mobilize during childbirth is a safe, effective way of providing optimum care to healthy women, it is a cost-effective way of reducing complications. Mobilization improves frequency, strength and length of contractions, decrease the use of oxytocin to augment labour and improves oxygen supply to the fetus. It improves alignment of pelvic bones and the shape and capacity of pelvis, and optimizes the good fit between fetus and pelvis. ${ }^{[8]}$
Prolonged labour may increase the risk of maternal and neonatal morbidity and mortality due to increase risks of mother exhaustion, postpartum haemorrhage, sepsis and fatal distress and requires early detection and appropriate medical response. Pharmacological measures are using to enhance contractions of the uterus and to decrease the duration of labour. These measures are costly and cause adverse effects on the women. ${ }^{[9]}$ Encouraging upright position during the first stage of labour has been a safe non-pharmacological intervention used for many years. It is an effective and safest intervention to increase the uterine contractions and to decrease the duration of labour; if not contraindicated. ${ }^{[10]}$

Nurses providing care in first stage of labor need to provide clear, consistent, and evidence based explanation of both the risks and benefits of the used positions and enable women to make decisions about the position choices which will afford the most comfort. Moreover, increasing a woman's sense of control may have the effect of decreasing the need for analgesia. ${ }^{[11]}$

\subsection{Significance of the problem}

Childbirth medicalization has reduced the parturient opportunity to labor and deliver in a spontaneous position, constricting women to assume the recumbent one. Birth positions are an important area of practice, in the past dominated by traditional and old practices. In recent years, this has been challenged by midwives, women and obstetricians, and the advantages of the upright position have been highlighted, supported by research and evidence. ${ }^{[7,12]}$ Also, the effects of different maternal positions during labor on maternal-fetal and neonatal outcomes are rarely in agreement and available evidences in this field are often controversial and fragmentary. There is a lack of studies which address the effect of two positions during the active phase of first stage of labor on labor outcomes at Benha University Hospitals. Hence, the current study aims to assess the effect of upright versus recumbent position during first stage of labor among primipare on labor outcome.

\subsection{Aim of this study}

This study aimed to assess the effect of upright versus recumbent position during the active phase of first stage of labor among primipara women on labor outcome in term of progress of labor, duration of labor, method of delivery, neonatal outcome and maternal satisfaction with assumed position.

\subsection{Research hypothesis}

The researchers hypothesized that the parturient women who assumes upright positions during the first stage of labor would be have faster progress of labor, shorten duration 
of labor, batter labor and neonatal outcome and higher satisfaction with this position compared to those who assume recumbent position.

\section{SUBJECTS AND METHOD}

\subsection{Research design}

Quasi-experimental research design was utilized to fulfill the aim of this study.

\subsection{Setting}

This study was conducted in labor unit of obstetric department at Benha University Hospital.

\subsection{Sampling}

Sample type: A purposive sample was used in collecting the data.

Sample size: A total of 100 parturient primipara were recruited in this study according to the following criteria: in early active phase of $1 \mathrm{st}$ stage of labor (i.e., from $4 \mathrm{~cm}$ to $6 \mathrm{~cm}$ cervical dilation), age between 20-35 years, with normal body mass index, labor occurring between gestational weeks 37 and 41, with a normal course of pregnancy, a single viable fetus with occipto anterior position, with spontaneous onset of labor, with intact membranes, free from any medical or obstetrical problems, and accepting to participate in the study.

Sampling technique: Data were collected for a period of six months, in order to avoid bias through data collection the parturient women with previous criteria and admitted to the previous study setting for first three months from beginning of data collection were recruited at the upright group $(n=50)$ which assumed one of upright positions as (standing, sitting, kneeling, squatting) during the active phase of first stage of labor and other parturient women with same criteria, who admitted at the second three months of data collection were recruited at recumbent group $(n=50)$ which assumed one of the recumbent positions as supine, semi recumbent, left lateral) during the active phase of first stage of labor.

\subsection{Tools for data collection}

Four tools were used for collecting data.

1) Structured interviewing questionnaire: It was designed and used by the researcher after reviewing the related literature. It consisted of two parts:

First part: Socio demographic data of studied sample such as (age, educational level, residence, occupation, and gestational age).

Second part: Initial assessment on admission such as (frequency, duration, interval and intensity of uterine contraction, cervical dilatation, fetal head decent and pain intensity).

2) Structured observational checklist: It was constructed by the researcher after reviewing related literature that covered the labour progress and labour and neonatal outcomes. It included:

a) Partograph as appointed by $\mathrm{WHO}^{[13]}$ is a graphic recording used to monitor the progress of labor in term of dilatation of cervical, the fetal head descent, progress of uterine contraction (duration, frequency, interval and intensity), duration of first, second and third stage of labor.

b) Apgar score as appointed by Virginia ${ }^{[14]}$ used to evaluate neonatal outcome. It is calculating by adding points $(2,1$, or 0 ) for heart rate, respiratory effort, muscle tone, response to stimulation, and skin coloration; a score of ten represents the good condition. It is done at first and fifth minutes after birth and if the score remains low may be repeated later. Score $(\leq 4)$ indicates sever asphyxia, (5-7) indicates moderate asphyxia and (8-10) indicates good condition.

3) Visual analogue pain intensity scale (VAS): It is a standardized linear scale developed by Freyd et al., ${ }^{[15]}$ and it was adopted and used by the researcher to assess the severity of pain. It is a self-reported $10 \mathrm{~cm}$ horizontal line which represents the subjective estimation of pain intensity. It comprises 0-10 point numerical scale, the two opposite ends representing no pain to severe pain as follows: No pain (0), Mild pain $(<4)$, Moderate pain(4-6), Sever pain (7-10).

4) Maternal satisfaction with assumed position: It is self reported assessment and containing two-item questionnaire developed by the researcher. Each parturient women were asked to respond to two questions: 1) Are you satisfied with your position assumed during 1st stage of labor? 2) Do you prefer this assumed position in the next labor? Their responses were recorded as either yes or no.

\subsection{Tools validity and reliability}

Tools content validity was reviewed for appropriateness of items by five an expert jury panel in the field of maternity nursing and obstetric medicine specialty. The questionnaires were modified according to the panel judgment on clarity of sentences and appropriateness of content. The reliability was done by Cronbach's Alpha coefficient test equal to 0.85 .

\subsection{Ethical considerations}

Ethical approval from the Nursing Faculty Ethical Committee of Benha University was obtained. Informed consent was obtained from enrolled women after clarifying the purpose of this study. Confidentiality of collecting data was maintained as well as respect of women's privacy was totally ensured. Each participant was informed that that participation is vol- 
untary and has a right to withdraw from the study at any time without given any reason.

\subsection{Pilot study}

The pilot study was carried out on $10.0 \%$ of the sample (10) parturient primipara to test the applicability and clarity of the study tools, as well as determine the time needed to fill the study tools and find out any problem that may interfere with the process of collecting data. And accordingly the necessary modifications were done in the form of added or omission of some questions. Women included in the pilot study were excluded from the main study sample.

\subsection{Procedure}

The following phases were adopted to fulfill the aim of the current study: Assessment, implementation, and evaluation phases. These phases were carried out from beginning of January 2016 to the end of June 2016 covering six months An official permission was granted from the Dean of the Faculty of Nursing, Benha University and delivered to the director of Benha University Hospital in order to obtain their approval for conduction of the research after explaining its purpose. The previous mentioned settings were visited by the researchers three days/week from 9.00 am and extended to 2 hours after delivery of the mother.

\subsubsection{Assessment phase}

This phase encompassed interviewing the parturient primipara to collect the socio-demographic data, the researchers greeted each women at the beginning of the interview, explained the aim, duration, and activities of the study and taken informed consent. Then each participant assigned to either upright or recumbent group according to their choose. The baseline data of labor condition, such as uterine contraction (duration, interval, frequency and intensity) cervical dilatation, fetal head descent/fifths were assessed on admission in both groups by the researcher by using tool (2) and assessed the level of pain by using tool (3).

\subsubsection{The implementation phase}

During this phase, parturient primipara in both groups were received the same management of first stage of labor according to the applied guidelines in study setting except for assumed position during 1st stage of labor. Each women in the upright group were individually met in the latent phase, mean while, an explanation of the benefits of changing their position from walking, standing, sitting, kneeling and squatting during first stage of labor. At the beginning of active phase of labor, women were encouraged to assume one of upright positions (i.e., walking and upright non-walking as sitting, standing, kneeling, or squatting). Walking out of bed and tell her to return to bed when medical or nursing intervention needed, sitting position was assumed on chair or in the bed with support the back, standing position with support on wall was achieved by herself. Each women were encouraged to assume such positions alternatively for the 15-20 minutes every one hour according to her comfort and in between women were permitted to lie down on bed for 10-15 minutes and advice her to repeated these position up to $10 \mathrm{~cm}$ cervical dilatation. And tell her to return in bed if the membrane ruptured. While, women in the recumbent group were assumed one of recumbent position as supine, semi recumbent and left lateral for 15-20 every hour and lasting more than $50 \%$ of the first stage of labor duration.

\subsubsection{The evaluation phase}

The researcher evaluated and compared the effect of the upright and recumbent positions during first stage of labor on progress of labor and labor outcomes, through assessing the progress of labor every hour in terms of duration, interval, frequency of uterine contraction, cervical dilatation, the descent of fetal head/fifth and pain intensity. Besides the duration of the first, second, third stage of labor, mode of delivery, neonatal condition using (tool 2, 3). Maternal satisfaction about the position they assumed and their preferences to this position in next labor were assessed using (tool 4).

\subsection{Statistical analysis}

The collected data were organized, categorized, tabulated and analyzed using the Statistical Package for Social Sciences (SPSS version 20.0). Descriptive statistics were applied (e.g., mean, standard deviation, frequency and percentages). Test of significance (chi square and paired $t$ test) was applied to test the study hypothesis. A statistically significant difference was considered at $p \leq .05$, and a highly statistically significant difference was considered at $p \leq .001$.

\section{RESUlts}

Table 1 shows socio-demographic data of the studied sample. It was reveled that $48 \% \& 56 \%$ of both upright and recumbent groups respectively were in age group (25-30) years with mean age $(26.18 \pm 4.08 \& 25.24 \pm 4.09)$ respectively, around half (48\% \& 54\%) of both groups had secondary education respectively. In addition, more than half of both groups $(54 \% \& 60 \%)$ are live in rural areas respectively. The majority $(82.0 \% \& 88.0 \%)$ of both groups were housewife respectively. There was no statistically significant differences between both groups related to their age, the level of education, occupation, residence and gestational age. 
Table 1. Distribution of the studied sample according to their socio-demographic data ( $\mathrm{n}=50$ for each group)

\begin{tabular}{|c|c|c|c|c|c|c|}
\hline \multirow{2}{*}{ Variable } & \multicolumn{2}{|c|}{ Upright group (50) } & \multicolumn{2}{|c|}{ Recumbent Group (50) } & \multirow{2}{*}{$\chi^{2}$} & \multirow{2}{*}{$p$} \\
\hline & No & $\%$ & No & $\%$ & & \\
\hline \multicolumn{7}{|l|}{ Age (years) } \\
\hline $20-<25$ & 3 & 6.0 & 2 & 4.0 & 0.93 & \\
\hline $25-<30$ & 24 & 48.0 & 28 & 56.0 & & .86 \\
\hline $30-35$ & 23 & 46.0 & 20 & 40.0 & & \\
\hline Mean \pm SD & \multicolumn{2}{|c|}{$4.08 \pm 26.18$} & \multicolumn{2}{|c|}{$25.24 \pm 4.09$} & & \\
\hline \multicolumn{7}{|l|}{ Educational level } \\
\hline Illiterate/read \& write & 4 & 8.0 & 3 & 6.0 & 2.04 & \\
\hline Primary/preparatory & 20 & 40.0 & 18 & 36.0 & & .56 \\
\hline Secondary & 24 & 48.0 & 27 & 54.0 & & \\
\hline University & 2 & 4.0 & 2 & 4.0 & & \\
\hline \multicolumn{7}{|l|}{ Occupation } \\
\hline Employed & 9 & 18.0 & 6 & 12.0 & 0.70 & .40 \\
\hline Housewife & 41 & 82.0 & 44 & 88.0 & & \\
\hline \multicolumn{7}{|l|}{ Residence } \\
\hline Rural & 27 & 54.0 & 30 & 60.0 & 1.96 & .16 \\
\hline Urban & 23 & 46.0 & 20 & 40.0 & & \\
\hline \multicolumn{7}{|c|}{ Gestational age at birth (weeks) } \\
\hline Mean \pm SD & 39.2 & & 39.6 & & 0.342 & \\
\hline
\end{tabular}

According to Table 2, the mean duration of uterine contraction in seconds among the upright and recumbent groups was $19.38 \pm 0.60 \& 19.40 \pm 0.49$ at baseline with no statistically significant difference, but after assuming upright position highly statistically significant difference between both groups in the 1 st hour was noticed $(26.10 \pm 0.24 \&$ $21.50 \pm 0.50)$ respectively, 2 nd hour $(44.94 \pm 1.73 \& 27.00$ $\pm 1.26)$ respectively, 3rd hours $(66.00 \pm 1.51 \& 35.62 \pm$ $0.63)$ respectively and 4 th hours $(70.80 \pm 1.98 \& 44.16 \pm$ 1.50) respectively. As shown the upright group had a higher mean duration of uterine contraction than the recumbent group $\left(p<.001^{*}\right)$. Table 2 also shows no statistically significant difference between both groups regarding interval of uterine contraction at baseline. In contrast in 1st hour after assuming upright position statistically significant differences were noticed between both groups for the favor of the upright group $(10.14 \pm 0.72)$ shows less interval than the recumbent group (12.48 \pm 0.50$)$. In 2nd, 3rd, and 4th hours (4.12 \pm $0.77,2.62 \pm 0.53 \& 0.95 \pm 0.05)$ respectively compared with higher mean score among the recumbent group (11.18 $\pm 0.39,8.24 \pm 0.42 \& 2.50 \pm 0.50$ ) respectively with highly statistically significant differences between both groups $(p<$ $.001 *)$.

As regards the mean number of uterine contractions/10 minutes, no statistically significant difference between both group at baseline assessment $(1.12 \pm 0.06 \& 1.56 \pm 0.65)$ respectively. However, after one hour statistically significant difference was noted between both groups. Also a highly statistically significant progress of frequency of uterine contractions $/ 10$ minutes was evident among the upright group in 2nd hour (4.06 \pm 0.71$)$, 3rd hour (4.88 \pm 0.33$)$, and 4th hour $(5.06 \pm 0.37)$. On the other hands the recumbent group shows slow progress of frequency of uterine contraction in the $2 \mathrm{nd}, 3 \mathrm{rd}$ and 4 th hours $(1.84 \pm 0.3,2.50 \pm 0.50 \& 3.58$ $\pm 0.50)$ respectively $(p<.001 *)$.

Table 3 shows no statistically significant differences between the upright and recumbent groups regarding intensity of uterine contraction before intervention $(p<.05)$. However, after assuming different position a highly statistically significant differences was obvious between both groups. The improvement in intensity of uterine contraction was evident among the upright group. Notably, in 1st hour (48.0\% \& $18.0 \%$ ) of the upright group had moderate and sever intensity compared to $(38.0 \% \& 14.0 \%)$ of the recumbent group. Moreover, marked progress in intensity in the upright group 2nd, 3rd and 4th hours $(22.0 \%, 70.0 \% \& 100.0 \%)$ had sever intensity compared to $(12.0 \%, 36.0 \% \& 66.0 \%)$ respectively of the recumbent group $(p<.001 *)$.

Table 4 reveals that there was no statistically significant difference between the upright and recumbent group in relation to cervical dilatation at baseline. However, a highly statistically significant difference was found between both groups in the 2nd, 3rd \& 4th hours after implementing different position as the upright group had a higher mean score of cervical dilatation $(5.68 \pm 0.47,9.02 \pm 0.32 \& 9.94 \pm 0.24)$ 
respectively compared to $4.08 \pm 0.80,5.54 \pm 0.50 \& 6.48 \pm$ 0.50 respectively of the recumbent group $(p<.001 *)$. Also no significant difference is recognized between both groups at baseline regarding the fetal head descent/fifth. A slight improvement in the head descent was noted among the upright group after one hour with significant difference and highly statistically significant after $2 \mathrm{nd}, 3 \mathrm{rd}, \& 4$ th hours from as- suming upright position. Concerning mean score of pain, no significant difference was noted between the both groups at baseline. However, one hour from assuming positions the upright group experienced less pain than the recumbent group $\left(p<.001^{*}\right)$. A high statically significant difference was noted between both groups after the 2 nd, 3 rd \& 4 th hours $(p<.001 *)$

Table 2. Distribution of the studied sample according to assessment of uterine contraction ( $\mathrm{n}=50$ for each group)

\begin{tabular}{|c|c|c|c|c|c|}
\hline \multirow[t]{2}{*}{ Variable } & \multicolumn{2}{|c|}{ Upright group (50) } & \multicolumn{2}{|c|}{ Recumbent Group (50) } & \multirow{2}{*}{ Paired $T$ test $(p)$} \\
\hline & $\mathbf{N}=\mathbf{5 0}$ & Mean \pm SD & $\mathbf{N}=\mathbf{5 0}$ & Mean \pm SD & \\
\hline \multicolumn{6}{|c|}{ 1-Duration of uterine contractions (seconds) } \\
\hline At baseline & 50 & $19.38 \pm 0.60$ & 50 & $19.40 \pm 0.49$ & $0.15(.89)$ \\
\hline After one hour & 50 & $26.10 \pm 0.24$ & 50 & $21.50 \pm 0.50$ & $4.49(<.048)^{*}$ \\
\hline After two hours & 50 & $44.94 \pm 1.73$ & 50 & $27.00 \pm 1.26$ & $9.45(<.0001)^{* *}$ \\
\hline After three hours & 50 & $66.00 \pm 1.51$ & 50 & $35.62 \pm 0.63$ & $13.54(<.0001)^{* *}$ \\
\hline After four hours & 6 & $70.80 \pm 1.98$ & 50 & $44.160 \pm 1.50$ & $5.66(<.0001)^{* *}$ \\
\hline \multicolumn{6}{|c|}{ 2-Interval of uterine contraction (minutes) } \\
\hline At baseline & 50 & $15.12 \pm 0.74$ & 50 & $14.88 \pm 0.52$ & $0.79(.049)^{*}$ \\
\hline After one hour & 50 & $10.14 \pm 0.72$ & 50 & $12.48 \pm 0.50$ & $0.045^{*}$ \\
\hline After two hours & 50 & $4.12 \pm 0.77$ & 50 & $11.18 \pm 0.39$ & $7.49(<.0001)^{* *}$ \\
\hline After three hours & 50 & $2.62 \pm 0.53$ & 50 & $8.24 \pm 0.43$ & $5.34(<.0001)^{* *}$ \\
\hline After four hours & 6 & $0.95 \pm 0.05$ & 50 & $2.50 \pm 0.50$ & $3.88(.001)^{* *}$ \\
\hline \multicolumn{6}{|c|}{ 3-Number of uterine contractions/10 minutes) } \\
\hline At baseline & 50 & $1.12 \pm 0.06$ & 50 & $1.56 \pm 0.65$ & $1.70(.32)$ \\
\hline After one hour & 50 & $2.78 \pm 0.41$ & 50 & $1.68 \pm 0.47$ & $3.12(.05)^{*}$ \\
\hline After two hours & 50 & $4.06 \pm 0.71$ & 50 & $1.84 \pm 0.37$ & $11.40(<.0001)^{* *}$ \\
\hline After three hours & 50 & $4.88 \pm 0.33$ & 50 & $2.50 \pm 0.50$ & $13.95(<.0001)^{* *}$ \\
\hline After four hours & 6 & $5.06 \pm 0.37$ & 50 & $3.58 \pm 0.50$ & $7.38(<.0001)^{* *}$ \\
\hline
\end{tabular}

"Statistically significant difference $(p<.05),{ }^{* *}$ A highly statistically significant difference $(p \leq .001)$.

Table 5 illustrates the percent distribution of the study women according to the duration of the 1 st, 2 nd and 3rd stage of labor. Duration of the 1 st stage was 10 to 12 hours of the upright group (92\%) compared to $66 \%$ of the recumbent group. However, the duration of the 2 nd stage of labor was 10 to 30 minutes of the upright group, $14 \%$ of compared to $(8 \%)$ of the recumbent group. On the other hand, duration of the 2nd stage more than 30 minutes to 1 hour among the majority (86\%) of the upright group compared to $56 \%$ of the recumbent group $(p<.001 *)$. Furthermore, the duration of the 3rd stage of labor was 10 to 20 minutes among the upright group (92\%) compared to $42 \%$ of the recumbent group. There were statistically significant differences between the upright and recumbent group regarding duration of 1st, 2nd and 3rd stage of labor.

Table 6 shows that $14.0 \%$ and $86.0 \%$ of upright group had spontaneous vaginal delivery and vaginal delivery with an episiotomy compared to $8.0 \% \& 92.0 \%$ of the recumbent group respectively, and $10.0 \% \& 10.0 \%$ had forceps or ventouse delivery in the recumbent group compared to nothing in upright group $(p<.04 *)$. Also all participant in upright group had spontaneous delivery of placenta compared to $98 \%$ in the recumbent group.

Table 7 shows significant difference between both groups in relation to Apgar score of the neonate during both first and fifth minute $(p<.05)$. Meanwhile, there was no statistical significance difference between both groups regarding admission of the neonate to neonatal intensive care unit.

Table 8 shows highly statistically significant differences between the upright and recumbent groups regarding satisfaction with assumed position and preference of this assigned position in the next labor $\left(p<.001^{*}\right)$. 
Table 3. Distribution of the studied sample according to intensity of uterine contraction ( $\mathrm{n}=50$ for each group)

\begin{tabular}{|c|c|c|c|c|c|}
\hline \multirow{2}{*}{ Intensity of uterine contractions } & \multicolumn{2}{|c|}{ Upright group (50) } & \multicolumn{2}{|c|}{ Recumbent Group (50) } & \multirow{2}{*}{$\chi^{2}(p)$} \\
\hline & No & $\%$ & No & $\%$ & \\
\hline \multicolumn{6}{|l|}{ Before assume different position } \\
\hline Mild & 45 & 90.0 & 43 & 86.0 & \multirow[t]{2}{*}{$0.77(.5)$} \\
\hline Moderate & 5 & 10.0 & 7 & 14.0 & \\
\hline \multicolumn{6}{|l|}{ 1st hour } \\
\hline Mild & 17 & 34.0 & 24 & 48.0 & \multirow{3}{*}{$29.54(<.001)^{* *}$} \\
\hline Moderate & 24 & 48.0 & 19 & 38.0 & \\
\hline Sever & 9 & 18.0 & 7 & 14.0 & \\
\hline \multicolumn{6}{|l|}{ 2nd hour } \\
\hline Mild & 4 & 8.0 & 15 & 30.0 & \multirow{3}{*}{$48.32(<.001)^{* *}$} \\
\hline Moderate & 35 & 70.0 & 29 & 58.0 & \\
\hline Sever & 11 & 22.0 & 6 & 12.0 & \\
\hline \multicolumn{6}{|l|}{ 3rd hour } \\
\hline Mild & 0 & 0.0 & 9 & 18.0 & \multirow{3}{*}{$57.24(<.001)^{* *}$} \\
\hline Moderate & 15 & 30.0 & 23 & 46.0 & \\
\hline Sever & 35 & 70.0 & 18 & 36.0 & \\
\hline 4th hour & $N=6$ & & $\mathrm{~N}=$ & & \multirow{4}{*}{$14.46(<.001)^{* *}$} \\
\hline Mild & 0 & 0.0 & 4 & 8.0 & \\
\hline Moderate & 0 & 0.0 & 13 & 26.0 & \\
\hline Sever & 6 & 100 & 33 & 66.0 & \\
\hline
\end{tabular}

Table 4. Distribution of the studied sample according to mean cervical dilatation $(\mathrm{cm})$, fetal head descent/fifths and mean pain scores ( $\mathrm{n}=50$ for each group)

\begin{tabular}{|c|c|c|c|c|c|}
\hline \multirow{2}{*}{ Variable } & \multicolumn{2}{|c|}{ Upright group (50) } & \multicolumn{2}{|c|}{ Recumbent Group (50) } & \multirow{2}{*}{ Paired $T$ test $(p)$} \\
\hline & $\mathbf{N}=\mathbf{5 0}$ & Mean \pm SD & $\mathbf{N}=\mathbf{5 0}$ & Mean \pm SD & \\
\hline \multicolumn{6}{|l|}{ 1-Cervical dilatation $(\mathrm{cm})$} \\
\hline Before assume different position & 50 & $3.26 \pm 0.69$ & 50 & $3.14 \pm 0.35$ & $0.53(.59)$ \\
\hline After one hour & 50 & $4.42 \pm 0.56$ & 50 & $3.62 \pm 0.53$ & $4.99(.037)^{*}$ \\
\hline After two hours & 50 & $5.68 \pm 0.47$ & 50 & $4.08 \pm 0.80$ & $13.38(<.001)^{* *}$ \\
\hline After three hours & 50 & $9.02 \pm 0.32$ & 50 & $5.54 \pm 0.50$ & $27.59(<.001)^{* *}$ \\
\hline After four hours & 6 & $9.94 \pm 0.24$ & 50 & $6.48 \pm 0.50$ & $29.76(<.001)^{* *}$ \\
\hline \multicolumn{6}{|l|}{ 3-Fetal head descent/fifth } \\
\hline Before assume different position & 50 & $4.80 \pm 0.40$ & 50 & $4.38 \pm 056$ & $2.28(.745)$ \\
\hline After one hour & 50 & $3.88 \pm 0.33$ & 50 & $4.14 \pm 0.35$ & $3.96(.009)^{* *}$ \\
\hline After two hours & 50 & $2.18 \pm 0.44$ & 50 & $4.02 \pm 0.14$ & $13.29(<.001)^{* *}$ \\
\hline After three hours & 50 & $0.85 \pm 0.11$ & 50 & $3.39 \pm 0.62$ & $25.11(<.001)^{* *}$ \\
\hline After four hours & 6 & $0.31 \pm 0.14$ & 50 & $3.11 \pm 0.53$ & $14.39(<.001)^{* *}$ \\
\hline \multicolumn{6}{|l|}{ Mean Pain Scores } \\
\hline Before assume different position & 50 & $7.61 \pm 0.47$ & 50 & $7.60 \pm 0.74$ & 0.136 \\
\hline After one hour & 50 & $6.64 \pm 0.48$ & 50 & $8.22 \pm 0.65$ & $(<.001)^{* *}$ \\
\hline After two hours & 50 & $6.84 \pm 0.37$ & 50 & $8.56 \pm 0.50$ & $(<.001)^{* *}$ \\
\hline After three hours & 50 & $7.38 \pm 0.49$ & 50 & $9.36 \pm 0.48$ & $(<.001)^{* *}$ \\
\hline After four hours & 6 & $7.68 \pm 0.47$ & 50 & $9.74 \pm 0.44$ & $(<.001)^{* *}$ \\
\hline
\end{tabular}

\footnotetext{
${ }^{* *}$ A highly statistically significant difference $(p \leq .001)$.
} 
Table 5. Distribution of the studied sample according to duration of first, second and third stage of labor ( $\mathrm{n}=50$ for each group)

\begin{tabular}{|c|c|c|c|c|c|c|}
\hline \multirow{2}{*}{ Variable } & \multicolumn{2}{|c|}{ Upright group (50) } & \multicolumn{2}{|c|}{ Recumbent Group (50) } & \multirow{2}{*}{$\chi^{2}$} & \multirow{2}{*}{$p$} \\
\hline & No & $\%$ & No & $\%$ & & \\
\hline \multicolumn{7}{|c|}{ Duration of 1st stage of labor (hours) } \\
\hline $8-<10$ & 4 & 8.0 & 0 & 0.0 & \multirow{3}{*}{23.14} & \multirow{3}{*}{$.000^{* *}$} \\
\hline $10-<12$ & 46 & 92.0 & 33 & 66.0 & & \\
\hline $12-14$ & 0 & 0.0 & 17 & 34.0 & & \\
\hline \multicolumn{5}{|c|}{ Duration of 2nd stage of labor (minute) } & \multirow{4}{*}{17.76} & \multirow{4}{*}{$.001^{* *}$} \\
\hline$<30$ minutes & 7 & 14.0 & 4 & 8.0 & & \\
\hline 30 minutes-one hour & 43 & 86.0 & 28 & 56.0 & & \\
\hline$>$ one hour & 0 & 0.0 & 18 & 36.0 & & \\
\hline \multicolumn{5}{|c|}{ Duration 3rd stage of labor (minute) } & \multirow{3}{*}{28.27} & \multirow{3}{*}{$.001^{* *}$} \\
\hline $10-20$ minutes & 46 & 92.0 & 21 & 42.0 & & \\
\hline 30 minutes $>20$ & 4 & 8.0 & 29 & 58.0 & & \\
\hline
\end{tabular}

Note. $\chi^{2}$ Chi-Square test. ${ }^{* *}$ Highly statistically significant differences $(p \leq .001)$.

Table 6. Distribution of the studied sample according to mode of delivery and mode of placental delivery ( $\mathrm{n}=50$ for each group)

\begin{tabular}{|c|c|c|c|c|c|c|}
\hline \multirow{2}{*}{ Variable } & \multicolumn{2}{|c|}{ Upright group (50) } & \multicolumn{2}{|c|}{ Recumbent Group (50) } & \multirow{2}{*}{$\chi^{2}$} & \multirow{2}{*}{$p$} \\
\hline & No & $\%$ & No & $\%$ & & \\
\hline \multicolumn{7}{|l|}{ Mode of delivery } \\
\hline Spontaneous vaginal delivery & 7 & 14.0 & 4 & 8.0 & & \\
\hline Vaginal delivery with an episiotomy & 43 & 86.0 & 46 & 92.0 & 71.61 & $.004^{*}$ \\
\hline Forceps delivery & 0 & 0.0 & 5 & 10.0 & & \\
\hline Ventouse delivery & 0 & 0.0 & 5 & 10.0 & & \\
\hline \multicolumn{7}{|l|}{ Mode of placental delivery } \\
\hline Spontaneous delivery & 50 & 100.0 & 49 & 98.0 & 86.16 & .06 \\
\hline Manual separation & 0 & 0.0 & 1 & 2.0 & & \\
\hline
\end{tabular}

Note. $\chi^{2}$ : Chi-Square test, ${ }^{*}$ Statistically significant difference $(p<.05)$

Table 7. Distribution of studied sample according to neonatal outcome ( $\mathrm{n}=50$ for each group)

\begin{tabular}{|c|c|c|c|c|c|c|}
\hline \multirow{2}{*}{ Variable } & \multicolumn{2}{|c|}{ Upright group (50) } & \multicolumn{2}{|c|}{ Recumbent Group (50) } & \multirow{2}{*}{ FET $/ \chi^{2}$} & \multirow{2}{*}{$p$} \\
\hline & No & $\%$ & No & $\%$ & & \\
\hline \multicolumn{7}{|l|}{ Apgar score at first minute } \\
\hline Good (8-10) & 32 & 64.0 & 19 & 38.0 & \multirow{3}{*}{6.99} & \multirow{3}{*}{$.003^{* *}$} \\
\hline Moderate asphyxia (5-7) & 15 & 30.0 & 24 & 48.0 & & \\
\hline Sever asphyxia $(\leq 4)$ & 3 & 6.0 & 7 & 14.0 & & \\
\hline \multicolumn{7}{|c|}{ Apgar score at fifth minute } \\
\hline Good (8-10) & 46 & 92.0 & 37 & 74.0 & \multirow{3}{*}{5.88} & \multirow{3}{*}{$.05^{*}$} \\
\hline Moderate asphyxia (5-7) & 3 & 6.0 & 11 & 22.0 & & \\
\hline Sever asphyxia $(\leq 4)$ & 1 & 2.0 & 2 & 4.0 & & \\
\hline \multicolumn{7}{|c|}{ Admission to the neonatal intensive care unit } \\
\hline Yes & 2 & 4.0 & 4 & 8.0 & & \multirow[t]{2}{*}{.06} \\
\hline No & 48 & 96.0 & 46 & 92.0 & & \\
\hline
\end{tabular}


Table 8. Distribution of the studied sample according to satisfaction with assumed position and preference of this position in the next labor ( $\mathrm{n}=50$ for each group)

\begin{tabular}{|c|c|c|c|c|c|c|}
\hline \multirow{2}{*}{ Variable } & \multicolumn{2}{|c|}{ Upright group (50) } & \multicolumn{2}{|c|}{ Recumbent Group (50) } & \multirow{2}{*}{$\chi^{2}$} & \multirow{2}{*}{$p$} \\
\hline & No & $\%$ & No & $\%$ & & \\
\hline \multicolumn{7}{|c|}{ Are you satisfied with your position assumed during 1st stage of labor } \\
\hline Yes & 39 & 78.0 & 13 & 26.0 & 6.99 & $.001^{* *}$ \\
\hline No & 11 & 22.0 & 37 & 74.0 & & \\
\hline \multicolumn{7}{|c|}{ Do you prefer this assumed position in the next labor? } \\
\hline Yes & 36 & 72.0 & 14 & 28.0 & 5.88 & $.001^{* *}$ \\
\hline No & 14 & 28.0 & 36 & 72.0 & & \\
\hline
\end{tabular}

\section{Discussion}

Despite a growing body of evidence reporting physical benefits for birthing women and their babies when women adopt an upright position, most women worldwide, with some few exceptions, currently give birth to their babies lying in a bed, on their backs which is a practice not based on systematic scientific research. ${ }^{[12]}$ The effect of upright versus recumbent position during first stage of labor on maternal-fetal and neonatal outcomes are rarely in agreement and available evidences in this field are often controversial and fragmentary. ${ }^{[16,17]} \mathrm{WHO}^{[18]}$ concluded that there is no evidence to support of recumbent position during the first stage of labor. But there is evidence that upright positions during the first stage of labor shorten the duration of labor and decreased intervention and not effects on mothers and fetus wellbeing. Therefore, maternity nurses should encourage women to take up whatever position they find most comfortable in the first stage of labor. This study has shed some lights on effect of upright versus recumbent position during first stage of labor among primipare on labor outcomes.

The results of this study will be discussed in frame of previously mentioned research hypothesis. As regards general characteristic of studied sample, the present study revealed that participants of both upright and recumbent groups were homogenous in demographic characters with no statistical significant difference. This homogeneity is useful in limiting extraneous variables, which may interfere with the effects of the intended intervention on labor progress and labor outcome. These findings were in the same line with Gizzo et al., ${ }^{[7]}$ who reported in their study about women's choice of positions during labor that no significant difference between upright and recumbent groups for age, educational level, gestational age. Regarding progress of uterine contraction it was obvious that women who assumed upright position during first stage of labor had improved the progress of uterine contraction, whereas no statistically significant differences between the upright and recumbent group at baseline assess- ment, however highly significant differences was evident among the upright group in term of increase number of uterine contraction/10 minutes, intensity and increased duration, as well as decreased interval during the $2 \mathrm{nd}$, 3rd and 4th hours after assumed upright position. Likewise, the recumbent group show less progress of uterine contraction. These findings may be that the upright positions may benefit from gravity effect which potentially prevent aortocaval compression, resulting in strengthened uterine contraction. Effective contractions are vital to cervical dilatation and fetal descent. This finding was in the same line with Lawrence et al. ${ }^{[3]}$ who studied the maternal positions and mobility during first stage labor and found that the strength of uterine contractions increased in the upright position compared to the supine position. Moreover agreed with Kumud et al. ${ }^{[9]}$ who studied the effect of upright positions on the duration of first stage of labor among nulliparous mothers and reported that parturient women who assumed upright positions had increase strength of uterine contractions than those assumed supine position.

Concerning the pain intensity the findings of the present study revealed high statistical significant differences between the upright and recumbent group in the Mean Pain Scores during the 2nd, 3rd, and 4th hours after assumed upright position. These may be due pain during the first stage of labor result from a combination of uterine contractions and cervical dilation. ${ }^{[19]}$ Painful sensations travel from the uterus through visceral afferent or sympathetic nerves that enter the spinal cord through the posterior segments of thoracic spinal nerves. Maternal physical and psychological comfort in labor is crucial for preventing additional stress. This can further be accomplished by allowing the mother to move freely and follow her body's signals to mobilize and change position during labor. These findings was in the same line with Angel Rajakumari et al. ${ }^{[20]}$ who studied the effectiveness of selected nursing measures on labor outcome among primigravid mothers and reported that mothers who maintained upright positions had significantly less pain than those 
in other position. Moreover, Chaillet et al. ${ }^{[21]}$ found that women who spent the early stage of labor in the upright position had less pain than in the supine position.

As regards cervical dilatation the present study findings showed significant improvement of cervical dilatation during the 2nd, 3rd and 4th hours of assuming the upright position than in the recumbent position. These findings may be due to that upright and mobile positions use the downward force of gravity which assists the fetal head to descent into the pelvis. As the head is applied directly and evenly on the cervix, uterine contractions are intensified in frequency, strength, and regularity. It is this uterine efficiency which help in cervical dilatation and effacement. The present study findings is compatible with the results of Hassan ${ }^{[22]}$ studied the effect of pelvic rocking exercise using sitting position on birth ball during the first stage of labor on its progress and found significant improvement of cervical dilatation in the study group after intervention than the control group. In addition, Lawrence ${ }^{[3]}$ found that women who assumed the upright position and frequently change it during the first stage of labor had improved cervical dilatation than those who assumed the supine position.

Concerning the descent of the fetal head the results of the current study showed a significant difference during the $2 \mathrm{nd}$, $3 \mathrm{rd}$ and 4 th hours after assuming upright position than in the recumbent position. These findings may be due to that upright position, movements with different positions increase strengthen of pelvic floor muscles, increase diameters of pelvis, and consequently help with descent of fetus into the vaginal outlet. The present findings is compatible with Gizzo et al. ${ }^{[7]}$ who found that vertical positions appeared helpful in descent of fetal head during labor, decreasing the rate of operative vaginal deliveries and cesarean delivery. Also these findings are in the same line with Simkin et al. and Storton ${ }^{[23,24]}$ who reported that the upright positions aid in bring the baby down by using gravity, whereas frequently changing maternal position moves the bones of the pelvis, helping the baby down in the pelvis.

Regarding duration of 1st, 2nd and 3rd stage of labor, the present study findings revealed a highly significantly shorter duration of three stages among the upright than the recumbent group. These findings may be due to that during the first stage of labor, upright positions such as sitting, standing and kneeling allow the abdominal wall to relax and influence gravity causes the uterine funds to fall forward. This directs the fetal head into the pelvic inlet in an anterior position and applies direct pressure to the cervix which helps to stimulate and stretch the cervix. An upright position during the second stage of labor has been associated with a decreased caesarean birth, instrumental delivery and reduction in labor duration. These findings are in agreement with Angel Rajakumari et al. ${ }^{[20]}$ who concluded that selected nursing measures is an effective method to reduce the duration of labor and enhances for the normal vaginal delivery. Also this results in same line with Hassan ${ }^{[22]}$ who revealed that a high significantly shorter duration of 1st, 2nd and 3rd stage of labor among the study group than the control group.

Additionally, this finding is in congruence with Lawrence et al. and Gizzo et al. ${ }^{[3,7]}$ the first concluded that the mean duration of labor among women who assumed alternative upright position was significantly less than those who are adopted supine or recumbent position. The second study, in the comparison of upright and ambulant positions versus recumbent positions during the first stage, concluded that labor is shorter by approximately one hour and $22 \mathrm{~min}$ for women randomized to upright as opposed to recumbent positions. As well as, this finding in the same line with Kumud et al. ${ }^{[9]}$ who found that the average reduction in the first stage of labor in experimental group was 2 hours.

Concerning mode of the delivery the findings of the present study revealed that the majority of participant in upright group had vaginal delivery with episiotomy compared the most in the recumbent group, and ten percent had forceps and ventouse delivery in the recumbent group compared to nothing in upright group. Also, all participant in upright group had spontaneous delivery of placenta compared to $98 \%$ in the recumbent group with no statistically significant difference. These findings are in the same line with Kumud et al. ${ }^{[9]}$ who found that women who assumed upright positions during the first stage of labor had vaginal delivery and no any women had delivered by using forceps and ventouse. On other hand, these findings disagree with Lawrence et al. ${ }^{[25]}$ who found that there were no significant differences between women randomized to upright versus recumbent positions in achieving spontaneous vaginal deliveries and assisted deliveries.

In relation to neonatal outcome the findings of present study revealed that a higher and good Apgar score of neonates among upright group when compared with recumbent group. Meanwhile, there was no significance difference between both groups regarding admission of the neonate to intensive neonatal care unit. These findings were disagree with Lawrence et al. ${ }^{[25]}$ who found no significant differences between the studied groups in terms of fetal distress and neonatal Apgar scores. Admission to neonate special care units was reported only in one study and more likely for babies delivered to mothers assigned to upright positions, but this difference did not reach statistical significance. 
As regards maternal satisfaction with positions were assumed, the findings of the present the study showed that more than three quarter of upright group was satisfied with assuming upright position compared to about one quarter of recumbent group was satisfied with recumbent position. Moreover, nearly three quarters in upright group were preferred to assume the upright position in the next labor compared to more than one quarter in recumbent group who anticipated to assume recumbent position in the next labor. These findings are in the same line with Prabhakar et al. ${ }^{[26]}$ who studied the effectiveness of ambulation during first stage of labor, on the outcome of labor among primigravida women and found that mothers were stay in bed and not walk around experienced lower satisfaction with childbirth than mothers that were walk around or move from one position to another. Also these findings supported by Hodnett et al. ${ }^{[10]}$ who found that women who encouraged to assuming upright position were satisfied and more comfortable. On the other hand this findings disagree with Mathew et al. ${ }^{[27]}$ who found that women who were choosing side lying or lying on back in first stage of labor were more satisfied.

\section{Conclusion}

Based on the findings of the present study, it can be concluded that the results of the present study support its hypothesis and revealed that assuming upright position during first stage of labor results in advantages for the parturient primipara woman by significant improvement in the progress of labor, shorten duration of the three stages of labor, faster fetal head descent, significant reduction of pain score and good Apgar score. And a highly statistical significant differ- ence regarding maternal satisfaction and preference of the assumed position in next labor.

\section{Recommendation}

Based on the findings of the present study, the following recommendations were suggested:

(1) All parturient women in low-risk labor should be informed about the benefits of assuming upright positions during first stage of labor, and be encouraged and supported to use them.

(2) In service education program for maternity nurses about different maternal positions during labor.

(3) Poster, pamphlets and video illustrating the benefit of upright positions should be available in antenatal clinics and labor unit.

(4) Replicated the study on a larger sample for generalizing the findings.

\section{ACKNOWLEDGEMENTS}

Researcher would like to thank all the mothers who participated in implementing of this study, all who have directly or indirectly helped me to complete this study and their support in each major step of the study.

\section{CONFlicts of InTEREST Disclosure}

It was enormous-time consuming to continue evaluate the effect of different maternal position on labor progress, labor outcome and neonatal outcome. The researcher excluded seven women from the study who didn't commit to the selected maternal position. All excluded women were replaced with other randomly selected participant.

\section{REFERENCES}

[1] Iravani M, Zarean E, Janghorbani M, et al. Women's needs and expectations during normal labor and delivery. Journal of Nursing and Midwifery Research. 2015.

[2] Perry SE, Lowdermilk DL, Cashion MC. Maternal Child Nursing Care. 3rd ed. Labor and Birth Process. 2014.

[3] Lawrence A, Lewis L, Hofmeyr GJ, et al. Maternal positions and mobility during first stage labor. Cochrane Database Syst Rev. 2013; 10: $1-10$.

[4] Priddis H, Dahlen H, Schmied V. What are the facilitators, inhibitors, and implications of birth positioning? A review of the literature. Women and Birth. 2012. PMid:21664208 https ://doi .org/10.1 016/j.wombi.2011.05.001

[5] Martin HJ, Martin RC. A narrative review of maternal physical activity during labor and its effects upon length of first stage. 2012.

[6] Leifer G. Maternity Nursing: An Introductory Text, 11th edition, Labor and Birth. 2013.

Published by Sciedu Press
[7] Gizzo S, Gangi SD, Noventa M, et al. Women's Choice of Positions during Labor: Return to the Past or a Modern Way to Give Birth? A Cohort Study in Italy. 2014.

[8] Edmonds K. Dewhurst's Textbook of Obstetrics and Gynecology. 8th ed. preterm Labor. 2015.

[9] Kumud Rana AK, Chopra S. Effect of upright positions on the duration of first stage of labor among nulliparous mothers. Nursing and Midwifery Research Journal. 2013.

[10] Alden KR, Lowdermilk DL, Cashion MC, et al. Maternity and Women's Health Care, 10th edition. Nursing Care Of The Family During Labor And Birth. 2014.

[11] Hodnett ED, Gates S, Hofmeyr GJ, et al. Continuous support for women during childbirth. Cochrane Database of Systematic Reviews. 2012. PMid:23076901 https ://doi.org/10.1002/14651858.C D003766. pub4

[12] Ward S, Hisley S. Maternal-Child Nursing Care Optimizing Outcomes for Mothers, Children, \& Families, (4th edition). The Process of Labor and Birth. 2015. 
[13] WHO. World Health Organization partograph in management of labor. Lancet. 1994; 343: 1399-1404. PMid:7910888

[14] Virginia. Apgar score "A proposal for a new method of evaluation of the newborn infant". Current Researches in Anesthesia \& Analgesia. 1953

[15] Freyd M. The graphic rating scale. Journal of Educational Psychology. 1923; 14: 83-102. https ://doi.org/10.1037/h0074329

[16] Gupta JK, Hofmeyr GJ, Shehmar M. Position in the second stage of labor for women without epidural anesthesia. The Cochrane Database of Systematic Reviews. 2012.

[17] Kemp E, Kingswood CJ, Kibuka M, et al. Position in the second stage of labor for women with epidural anesthesia. Cochrane Database of Systematic Reviews. 2013.

[18] The WHO. Reproductive Health Library (RHL) Maternal positions and mobility during first stage of labor. Geneva: WHO. 2015.

[19] Gabbe SG, Niebyl JR, Simpson JL. (Eds.). Obstetrics: Normal and Problem Pregnancies (5th ed.). New York, NY: Churchill Livingstone. 2014.

[20] Angel Rajakumari G, Sheela R, Soli TK. The effectiveness of selected nursing measures on labor outcome among primigravid mothers. Journal of Science. 2015; 5(8): 716-719.

[21] Chaillet N, Belaid L, Crochetière C. Non pharmacologic approaches for pain management during labor compared with usual care: A meta-analysis. Birth. 2014; 41: 122-37. PMid:24761801 https: //doi.org/10.1111/birt.12103
[22] Hassan NZ. Effect of pelvic rocking exercise using sitting position on birth ball during the first stage of labor on its progress. IOSR Journal of Nursing and Health Science (IOSR-JNHS). 2016; 5(4): 19-27.

[23] Simkin P, Ancheta R. The labor progress handbook: Early interventions to prevent and treat dystocia. 3rd ed. New York, NY: WileyBlackwell. 2011.

[24] Storton S. The coalition for improving maternity services: Evidence basis of mother-friendly care. Step 4: Provide the birthing woman with freedom of movement to walk, move, and assume positions of her choice. The Journal of Prenatal Education. 2013; 16(Supp. 1): 25S-27S. PMid:18523670 https ://doi.org/10.1624/1058 $12407 \mathrm{X} 173164$

[25] Lawrence A, Lewis L, Hofmeyr GJ, et al. Maternal positions and mobility during first stage labor. Cochrane Database of Systematic Reviews. 2011; 15(2).

[26] Prabhakar D, George LS, Karkada S. Effectiveness of ambulation during first stage of labour, on the outcome of labour among primigravid women in selected hospitals of Palakkad District, Kerala. International Journal of Nursing Education. 2015; 7(1): 1-6. https://doi.org/10.5958/0974-9357.2015.00001.X

[27] Mathew A, Nayak S, Vandana K. A Comparative study on effect of ambulation and birthing ball on maternal and newborn outcome among Primigravida mothers In selected Hospitals In Mangalore. Nitte University Journal of Health Science. 2012; 2(2): 2249-7110. 